\title{
AN ASSESSMENT OF THE FEASIBILITY OF DISCHARGE OF PATIENTS IN HOSPITALS FOR THE SUBNORMAL
}

\author{
THOMAS McKEOWN, M.D., Ph.D., F.R.C.P. \\ AND \\ J. R. TERUEL, M.D. \\ Department of Social Medicine, The University, Birmingham
}

IT is now widely accepted that subnormal patients who do not require hospital services should not be in hospital but should be in hostel-type accommodation under educational and welfare authorities if they cannot be cared for in their own homes. However, the application of this policy to patients already in hospital presents difficulties, both because there are differences of opinion about the proportion of patients who do not need hospital care and because even among patients whose discharge would be desirable it is not clear to what extent it is feasible, particularly in the case of those for whom hospital has been home, sometimes their only home, for many years.

The purpose of the present investigation is to assess the proportion of Birmingham patients now in hospital who could in practice be discharged (not necessarily the same as the proportion who, on grounds of medical or other needs, do not need hospital care). A previous estimate (McKeown and Leck, 1967) had suggested that only about half of the Birmingham patients in hospitals for the subnormal needed the kind of care-essentially investigation, active treatment or the attention of trained nursing staff-which made it essential for them to be in hospital. This estimate was questioned by some consultants, working in the field of subnormality, on the grounds that it was based on an appraisal of medical, nursing, and other needs rather than a direct question to the consultant. In examining the feasibility of discharge we have therefore reassessed the proportion of patients needing to be in hospital, basing the estimate on the consultant's classification of his own patients.

In the previous enquiry all $(1,652)$ Birmingham patients in hospitals for the subnormal were included. For the present purpose it was considered sufficient to cover all (204) children under 16 and a random sample of 339 patients comprising one in four of those over this age.

Consultants were asked to assign each of their patients to one of six classes according to the type of care required-investigation or active hospital treatment; mental and basic nursing; mental nursing; basic nursing; checking and counselling; and sheltered environment. This is the classification used previously, with types of care arranged in order of decreasing complexity and each patient uniquely classified according to the most complex type of care required. Patients under the first four headings were considered to need hospital care and those under the last two were not.

Since the earlier conclusions were questioned, we should clarify the changes in the present procedure Previously, consultants and ward sisters were asked to see each of their patients together and to provide? detailed information concerning their medical, nursing, and other needs, and these data were used to prepare the six-fold classification. In the present case consultants were invited to place patients directly into one of the six classes, and any differences between the results are due either to changes in the patients' needs since the previous survey or to the difference in procedure.

Tables I and II show the classification of children and adults respectively according to the types of care required. (For a number of reasons, including particularly the greater scope for hospital investigation and active treatment, it was considered desirable to

TABLE I

CLASSIFICATION OF CHILDREN UNDER 16 ACCORDING TO TYPE OF CARE REQUIRED

\begin{tabular}{|c|c|c|c|c|}
\hline Care Required & Male & Female & Total & $\%$ \\
\hline $\begin{array}{l}\text { Investigation or active } \\
\text { treatment } \\
\text { Mental and basic nursing } \\
\text { Mental nursing only } \\
\text { Basic nursing only } \\
\text { Checking and counselling } \\
\text { only } \\
\text { Sheltered environment }\end{array}$ & $\begin{array}{r}21 \\
46 \\
5 \\
34 \\
10 \\
8\end{array}$ & $\begin{array}{r}15 \\
15 \\
7 \\
32 \\
8 \\
3\end{array}$ & $\begin{array}{l}36 \\
61 \\
12 \\
66 \\
18 \\
11\end{array}$ & $\begin{array}{r}18 \\
30 \\
6 \\
32 \\
14\end{array}$ \\
\hline Total & 124 & 80 & 204 & 100 \\
\hline
\end{tabular}


TABLE II

CLASSIFICATION OF PATIENTS AGED 16 AND OVER ACCORDING TO TYPE OF CARE REQUIRED

( 1 in 4 sample)

\begin{tabular}{l|c|c|c|c}
\hline \multicolumn{1}{c|}{ Care Required } & Male & Female & Total & $\%$ \\
\cline { 1 - 2 } $\begin{array}{l}\text { Investigation or active } \\
\text { treatment }\end{array}$ & 2 & 5 & 7 & 2 \\
Mental and basic nursing & 59 & 56 & 115 & 34 \\
Mental nursing only & 25 & 31 & 56 & 17 \\
Basic nursing only & 26 & 32 & 58 & 17 \\
$\begin{array}{l}\text { Checking and counselling } \\
\text { only }\end{array}$ & 28 & 26 & 54 & 16 \\
Sheltered environment & 28 & 21 & 49 & 14 \\
\hline \multicolumn{1}{c|}{ Total } & 168 & 171 & 339 & 100 \\
\hline
\end{tabular}

give separately the results for children.) There are two notable differences from the previous results. The first is the higher proportion of patients considered to need investigation or active treatment$18 \%$ of children and $2 \%$ of adults, compared with the earlier estimate of $0.4 \%$ for patients of all ages. The second difference is the lower proportion of patients thought not to need hospital care-a little less than 1 in 3 , while the previous estimate was about 1 in 2. We shall comment later on these differences after considering the main subject of the present investigation, namely, the possibility of discharge from hospital.

Assessment of the feasibility of discharge is based on (a) consideration of patients' home circumstances and $(b)$ consultants' opinions of the suitability of their patients for hostel care.

\section{Feasibility of Home CARE}

From data available in hospital, either in records or from staff (doctors, nurses or social workers), it was known whether patients still had a home and, if so, whether the home was likely to be capable of accepting the return of a subnormal relative. The results are summarized in Table III for the 29 children and 103 adults (from the 1 in 4 sample) considered not to need hospital care.

TABLE III

ASSESSMENT OF HOME CIRCUMSTANCES

\begin{tabular}{|c|c|c|}
\hline & Children & Adults $^{2}$ \\
\hline $\begin{array}{l}\text { No home } \\
\text { Home available: unsatisfactory because of: } \\
\text { Social conditions } \\
\text { Not wanted by relatives } \\
\text { Family unable to cope } \\
\text { Mother ill }\end{array}$ & $\begin{array}{l}3 \\
8 \\
5 \\
5 \\
2 \\
6\end{array}$ & $\begin{array}{r}59 \\
19 \\
5 \\
3 \\
5 \\
12\end{array}$ \\
\hline Total & 29 & 103 \\
\hline
\end{tabular}

${ }^{1} 1$ in 4 sample
They leave little doubt that discharge to their own homes would be possible for relatively few patients now in hospital. Most either have no home (more than half the adults) or, if they have a home, it is unsatisfactory for one of several reasons-poor social conditions; the family unable or unwilling to accept responsibility; and, in a few cases, illness of the mother, which would make discharge impracticable or undesirable.

There were six children whose discharge appeared to be feasible on grounds of their own requirements and family circumstances. These patients were already known to the hospital staff and, even without the present investigation, would soon have been discharged; one was due to leave within a few days. On this evidence there is no reason to think there was any considerable scope for discharge home of children already in hospital.

There were 12 adults in the sample (equivalent to approximately 48 in the total Birmingham hospital population) judged not to need hospital care and with homes which were considered generally satisfactory. It is more difficult to assess the feasibility of discharge than in the case of children, mainly because several patients had been in hospital for quite a long time, two for more than 50 years. After prolonged hospital care it may be difficult both for the patient to accept a different environment and for the home to make the necessary adjustments; and without a trial it is not possible to be confident about the proportion who could live at home. There were, however, two patients whose discharge seemed quite feasible, and a few others in hospital for relatively short periods for whom it could be seriously considered. Even so, among adults, as in the case of children, the scope for discharge to their own homes of patients now in hospital appears to be quite small.

\section{Feasibility of Hostel Care}

Of the 29 children considered not to need hospital care, 23 either had no home or, more commonly, for various reasons could not be discharged to it. Of these children, 21 were thought suitable for hostels (Table IV).

TABLE IV

ASSESSMENT OF FEASIBILITY OF HOSTEL CARE

\begin{tabular}{l|c|c}
\multicolumn{1}{c|}{ Hostel Care } & Children & Adults $^{1}$ \\
\hline Feasible & 21 & 85 \\
Feasible with reservations & 0 & 11 \\
Not feasible & 2 & 7 \\
\hline Total & 23 & 103 \\
\hline
\end{tabular}

${ }_{11}$ in 4 sample 
At first sight it seems inconsistent that the remaining two children were not recommended for hostels, although in Table I they were classified as needing only a sheltered environment. This anomaly reflects the difficulty of classification in borderline cases, a problem which also arises with adults (referred to below). For inevitably when a number of patients are assessed, a few who are judged not to require hospital care may nevertheless be thought unsuitable for a hostel. Probably the most common reason is that the patient has been too long in hospital to be able to live anywhere else.

The problem is relatively larger in the case of adults. Of the 103 considered not to need hospital care (Table IV), 7 were judged unsuitable for hostels and a further 11 were recommended with reservations because of certain needs which would have to be met. These needs included, for example, careful supervision (the most common requirement), medical attention, and, in one case, occasional short periods in hospital.

There remained 85 patients whose care in hostel was thought by the consultants to be quite feasible. But a close inspection of these cases suggested that the hostel admission of 18 of them might be in the nature of a trial, either because they had spent many years in hospital or because of behavioural problems which might make them difficult to manage under hostel conditions.

We therefore conclude that there were 21 children (not including the 6 to be discharged to their homes) and 67 adults for whom hostel care seemed quite feasible. There were approximately 29 more adults whose hostel admission could reasonably be investigated, with the understanding that some of them might prove unmanageable and would have to return to hospital.

\section{Discussion}

The results of the initial classification of patients (Table I) differ in two respects from those of the previous investigation (McKeown and Leck, 1967): the proportion of patients judged to need investigation or active treatment is somewhat higher; and the proportion not needing hospital care is lower. The first difference probably reflects a substantial increase in the frequency of active measures, particularly in the care of children. The second difference must be attributed either to a change in patients' needs within the period between the investigations or, more probably, to a change in the method of classification. In the first survey assessment of the need for hospital care was derived from appraisal of a considerable body of information concerning medical, nursing, and other needs; in the second, it was obtained by direct questions to consultants.

There is something to be said for both procedures: for the first, that it rested on a careful examination by disinterested observers of data provided by the hospital staff; and for the second, that it gave the consultants more scope for clinical judgement. Instead of attempting to defend either procedure, however, it seems more profitable to accept that, taken together, they indicate that the proportion of patients now in hospitals for the subnormal who do not need hospital care is considerable, probably between 1 in 2 and 1 in 3 . The present paper is based on the lower estimate from the recent survey.

Its chief purpose was to examine the feasibility of care outside hospital. For while patients may be judged not to need hospital care, it by no means follows that in all cases they could be discharged, particularly after prolonged periods in an institution. The possibilities which require assessment are the feasibility of home care and of hostel care.

The results suggest that there is little scope for discharge of patients to their own homes, either because they have no home or because it is for various reasons unsatisfactory. Nevertheless there are a small number of adults who do not need hospital care whose return home could usefully be considered.

Assessment of the feasibility of hostel admission is inevitably somewhat academic when few suitable hostels exist and when, even nationally, there has been no considerable experience of hostel care of the subnormal. But, so far as they go, the results suggest that at least one-fifth of the patients now in hospital could be cared for in hostels or, in a few cases, in their own homes. This estimate is based on 27 children judged suitable for home or hostel care and 67 adults (from a 1 in 4 sample) judged suitable for hostel care, from an estimated total population of 1,560 Birmingham patients in hospitals for the subnormal (204 children $+4 \times 339$ adults).

It goes almost without saying that these estimates understate, perhaps greatly, the scope for future reductions in numbers of subnormal patients in hospital. The present situation is the result of serious and long-standing deficiencies-inadequate assessment and active treatment; admission of patients who should not be in hospital; retention of patients who should have been discharged; and lack of alternative facilities with the requisite educational and occupational opportunities. In spite of these deficiencies at least one-fifth of patients could be discharged to suitable accommodation in the community, and it can hardly be doubted that with fully developed medical, educational, and welfare services 
the number of patients needing to be in hospital could be still further reduced.

\section{SUMmaRY}

The feasibility of discharge from hospital was assessed by consultants for all (204) Birmingham children under 16 in hospitals for the subnormal and for a random sample of 339 patients comprising 1 in 4 of those over this age. Approximately one-third of the patients were thought not to need hospital care and about one-fifth were considered suitable for discharge to their own homes or, more commonly, to hostel accommodation. There were additional patients with some special requirements whom it would be reasonable to admit to hostels, but some of them would probably prove unsuitable. These estimates reflect long-standing deficiencies, and with fully developed medical, educational, and welfare services the number of patients needing to be in hospital could be reduced further.

For collaboration in assessment of patients' needs we are indebted to the staffs of hospitals for the subnormal in the Birmingham area. The data were collected and analysed with the help of Miss Ida Giles.

\section{REFERENCE}

McKeown, T., and LECK, I. (1967). Institutional care of the mentally subnormal. Brit. med. J., 3, 573 . 